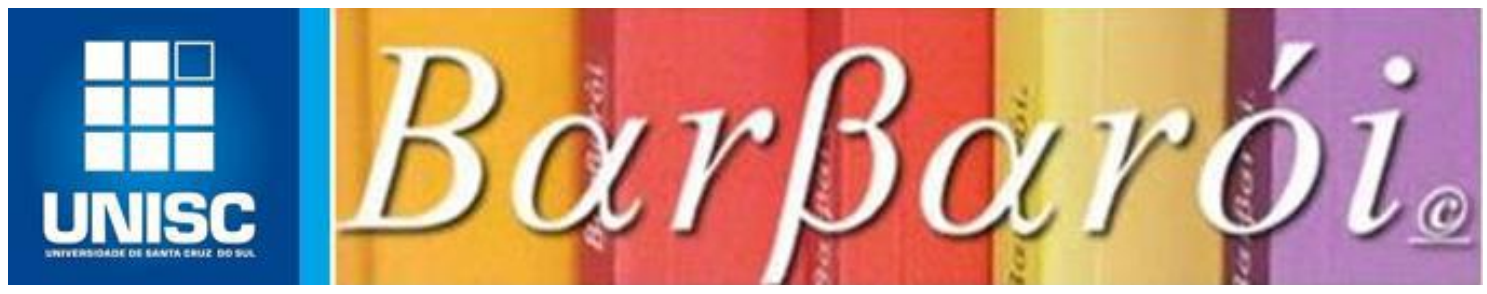

\title{
FUNCIONALIDADES CARPINTADAS: IMAGINÁRIOS CAMBIADOS ENTRE ESCOLA E COMUNIDADE
}

DOI: http://dx.doi.org/10.17058/barbaroi.v1i53.12390

\author{
$*$ \\ Luciano Plez Melo \\ Universidade Estadual Paulista Júlio de Mesquita Filho - UNESP-RC - Brasil \\ Leila Maria Ferreira Salles \\ Universidade Estadual Paulista Júlio de Mesquita Filho - UNESP-RC - Brasil

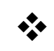

\begin{abstract}
Resumo
A reflexão contida neste trabalho é resultado de pesquisa realizada no período de 2011 a 2013, em escola pública do distrito de Igaraí, na cidade de Mococa, interior do Estado de São Paulo - Brasil, buscando possibilidades de percepção de imaginários e funcionalidades erigidas sobre e para a unidade escolar, junto a seus atores e distrito. Valendo-nos dos documentos produzidos pela unidade escolar, referência documental sobre o distrito e também de análise de entrevistas concedidas por atores envolvidos na constituição da vida escolar, encontramos localidades interpenetradas e em movimentos diversos, assincrônicos, cujas próprias funcionalidades declaradas e imaginadas mantinham-se precariamente sob constante negociações.
\end{abstract}

Palavras chave: escola, funcionalidade, imaginários

\section{Apresentação}

Este trabalho é decorrente de pesquisa realizada em escola estadual do distrito de Igaraí, município de Mococa, a aproximadamente 260 quilômetros de São Paulo, Capital do Estado, em período compreendido de 2011 a 2013. A escola constituiu-se como objeto de atenção devido ser a única unidade escolar do distrito abrangendo desde o primeiro ciclo do ensino fundamental ao ensino médio em suas dependências. Esclarecemos aqui que este período se deu pela concomitância ao desenvolvimento e término de Projeto Político Pedagógico norteador da gestão escolar no período de 2007 a 2010 e início de gestão norteada pelo Projeto Político Pedagógico de 2011 a 2014, marcado também pela transição de diretores, respeitando intervalo similar para a gestão escolar de sucedido e sucessor.

O distrito, local em que a escola se localiza, possui uma população aproximada de 3.000 habitantes e destes, segundo dados encontrados no projeto político pedagógico da escola, Barbarói, Santa Cruz do Sul, n.53, p.<117-140>,jan./jun. 2019 
cinquenta por cento residir na zona rural do distrito. Nessa localidade há dificuldade de acesso da população local a equipamentos de Estado, pois excetuando a unidade escolar objeto deste estudo, há apenas uma creche municipal e um posto de saúde, mesmo que o distrito conte com subprefeitura local.

Embora a dificuldade ao acesso a equipamentos de Estado também decorrer de geograficamente o distrito localizar-se a vinte e sete quilômetros aproximados da sede do município de Mococa - SP, o trajeto constituído em via sinuosa e que mesmo não sendo único, dá-se ímpar pela impossibilidade da distância e duração do trajeto, existam poucas alternativas de uso e horários de transporte coletivo; há no distrito alguma migração de alunos quando do ingresso no ensino médio a escolas da sede do município, mesmo com oferta de vagas locais.

Isto posto e partindo das ponderações de Castoriadis na "Instituição Imaginária da Sociedade" (1975), buscamos observar a unidade de ensino visando refletir sobre como os atores / autores nela inseridos e os do seu entorno apreendem os componentes funcionais da escola que acabam por legitimar sua própria funcionalidade, buscando encontrar indícios de bases imaginárias para essa legitimação. Coube-nos então o estabelecimento do viés de entrada à investigação, condição que nos conduziu à observação de pragmática de superfície da escola, possuindo como pano de fundo, tentativa de apreensão ou percepção de imaginários instituintes desta pragmática e formas ou mecanismos de câmbio destas práticas com a comunidade local.

A pragmática de superfície aqui mencionada referiu-se a conjunto de ações / práticas denotadas ou gravitadas em torno de dado significante, porém, sem a estruturação necessária de rito ou ainda pertencente de forma plena a certa racionalidade instituída-instituinte. Estas ações não se dão necessariamente como sincrônicas ao elemento significante indicador "do que fazer”, uma vez que podem conotar qualquer tipo de resistência à proposição e ou regulação carregada no significante.

Para tanto, a partir de indagações sobre a utilidade da escola, as formas de construção / representação da utilidade a diferentes atores envolvidos no cotidiano escolar, tentamos perceber se a pragmática de superfície grafava-se também por profundidade como marco regulatório nas relações entre atores-escola-atores / escola-atores-escola.

Toda a nossa investigação alicerçou-se em provocação de Castoriadis mantida na instituição constituir-se como "uma rede simbólica, socialmente sancionada, onde se combinam em proporções e em relações variáveis um componente funcional e um componente imaginário", (Casotoriadis, 1995, p.159), implicando daí sua concepção de alienação e ainda a extensão propositiva de a sociedade relacionar-se com as instituições à maneira dos imaginários constituídos por si. Desta provocação, um de nossos problemas na tentativa de compreensão do Barbarói, Santa Cruz do Sul, n.53, p.<117-14O>,jan./jun. 2019 
ora proposto por Castoriadis constitui-se, em acordo com o próprio, em a sociedade manter-se como "magma" e sua admissão da dificuldade de apreensão dos processos de construção e percepção dos imaginários instituídos a partir de instrumentais analíticos erigidos sob égides de lógicas identitárias e ou conjuntistas.

Neste quadro de precariedade grafou-se o componente funcional das instituições como objeto tangível, perceptível mesmo que em relações de superfície, pontuando como hipótese geral da investigação a possibilidade de apreensão de marcas do imaginário nas periferias dos processos de compreensão dos componentes funcionais de dada instituição.

O percurso investigativo iniciou-se tendo como base de dados os documentos oficiais e entrevistas semiestruturadas de ao menos um representante dos diversos segmentos escolares. $\mathrm{Na}$ escola concederam entrevistas espontaneamente: diretor e um coordenador pedagógico; além dos atores internos diretamente envolvidos no cotidiano escolar, buscamos também em atores externos, para nossa maior percepção sobre a escola objeto, como a realização de entrevista com ex-diretor, morador no distrito, morador que havia participado em órgão colegiado da escola, doadores do terreno para a construção da escola, constituindo para estes a condição de sujeitos na investigação.

O ponto de partida em nosso intento para conhecer o distrito foi a busca por referências estatísticas junto ao Instituto Brasileiro de Geografia e Estatística - IBGE. Quando do contato com tal fonte, verificamos que os dados referentes ao Censo de 2010 sobre o distrito permaneciam aglutinados aos dados do município, sendo naquele momento impossível a distinção de quais referências diziam respeito ao distrito especificamente. Frente a isto partimos para o levantamento de dados junto a Prefeitura do Município de Mococa encontrando algumas referências sobre o distrito junto ao Cadastro Imobiliário Municipal.

A tentativa de percepção do distrito de Igaraí por meio de registros documentais é marcada por grande dificuldade de obtenção de dados organizados e também dispersos sobre o distrito, isto levou-nos a composições de algumas marcas para leitura amparada em dados de Cartório Eleitoral local e Cadastro Imobiliário da Prefeitura Municipal, a exemplo.

Dada a dificuldade de acesso a dados sobre o distrito a alternativa para o seu delineamento foi examinar os requerimentos encaminhados à Câmara Municipal de Mococa, durante o período de recorte deste estudo que continham como referência o distrito de Igaraí.

Isto assumido, pontuamos como princípio para análise a produção de "análise de conteúdo" (Bardin, 2011), em documentos / registros oficiais da escola acompanhada da produção de análise de entrevistas semiestruturadas colhidas de diversos atores envolvidos no cotidiano escolar. 
De forma paralela, seguimos à busca de registros continentes de referências sobre o distrito de Igaraí, pensando ao encontro a aplicação de mesmo exercício de análise para alguma descrição do mesmo. Porém, neste caminho que exigiu toda uma imersão e estada nas localidades, estadas estas não planejadas a princípio para o processo de pesquisa, a busca pelos objetos e alguns de seus elementos significantes nos proporcionou uma "experiência etnográfica", à medida da proposição de Magnani (2009), quando de sua reflexão sobre a etnografia como método em sentido amplo para a antropologia, porém não exclusivo, distinguindo a prática etnográfica de sua experiência pontuando: "é que se deve distinguir entre "prática etnográfica" de "experiência etnográfica": enquanto a prática é programada, contínua, a experiência é descontínua, imprevista." (Magnani, 2009 p. 136).

A experiência etnográfica se fez por encontrarmos ao longo de nosso processo de pesquisa a composição de objetos em constante fluxo, movediços, caleidoscópicos, exigindo para a carpintaria de alguns rascunhos, carpintaria de paredes precárias a tentativa da aplicação das ferramentas em movimento.

\section{Da base teórica}

O nosso olhar investigativo para a escola e distrito pontuou-se na proposição castoriadiana da constituição do mundo humano como criação do processo de autoinstituição da sociedade, fazendo do próprio social-histórico produto-produção de um imaginário social "em sentido radical", distanciado de qualquer apriorismo ou determinações "naturais ou históricas" e desse modo tomamos que:

História é criação; criação de formas totais de vida humana. As formas sociaishistóricas não são "determinadas" por "leis" naturais ou históricas. A sociedade é autocriação. Quem cria a sociedade e a história é a sociedade instituinte, em oposição a sociedade instituída,imaginário social em sentido radical. A auto-instituição da sociedade é a criação de um mundo humano: de coisas, de realidade, de linguagem, de normas, de valores, de modos de viver e de morrer, objetivos pelos quais vivemos e pelos quais morremos - e, obviamente, em primeiro lugar e acima de tudo, ela é criação do indivíduo humano no qual a instituição da sociedade está solidamente incorporada. (Castoriadis, 1986. p.271)

E ainda:

assim como a sociedade não pode ser pensada dentro de nenhum dos esquemas tradicionais da coexistência, a história não pode ser pensada dentro de nenhum dos esquemas tradicionais de sucessão. Porque o que se dá em e pela a história não é sequência determinada do determinado, mas emergência da alteridade radical, criação imanente, novidade não trivial. (Castoriadis, 1975. p. 220)

Um imaginário radical dado como criação incessante e essencialmente indeterminada (social-histórica e psíquica) de figuras / formas / imagens a partir das quais somente é possível 
falar-se de "alguma coisa" promovendo àquilo que denominamos "realidade" e "racionalidade" como seus produtos (Castoriadis, 1975, p. 13). Isto traz consigo a percepção sobre a imaginação criadora manter-se como

capacidade de colocar uma nova forma. De um certo modo, ela utiliza os elementos que aí estavam, mas a forma, enquanto tal, é nova. Mais radicalmente ainda, a imaginação é que nos permite criar o mundo, ou seja, apresentarmos alguma coisa, da qual sem a imaginação não poderíamos nada dizer e sem a qual não poderíamos nada saber. (Castoriadis, 1992. p.89)

Tal percepção acarreta ao projeto castoriadiano a necessidade da elaboração de um espaço que mesmo não sendo continente de pura indeterminação não se constitua em antípoda como ordem / determinação. Entre o “caos" e o "cosmos" e interpenetrando-os há um solo magmático:

\begin{abstract}
Não podemos pensar a realidade em termos de ordem (cosmos) ou desordem (caos), apenas. Entre ambos, é preciso situar uma espécie de terceira dimensão, denominada magmática, aquela que responde pelas realidades "inconsistentes" e fluidas, mais próximas do fluxo heraclitiano que da permanência parmenidiana. Existe uma dimensão fluida, aberta (criadora) da realidade, presente especialmente no mundo das significações, no inconsciente, e no social-histórico, que não é captada pela lógica identitária (Losada, 2009. p. 48)
\end{abstract}

Mantivemos, contudo, a hipótese geral da pesquisa sobre a possibilidade de apreensão de marcas do imaginário nas periferias dos processos de compreensão dos componentes funcionais de dada instituição; a possibilidade de apreensão de um imaginário social, ou elementos imaginários de uma escola em particular nas bases e movimentos constitutivos / legitimadores de sua funcionalidade.

Assim, em referência geral à funcionalidade tomamos também precariamente a noção de utilidade, de útil, do princípio de utilidade benthaniano, quando este propõe como postulado em "Uma Introdução aos Princípios da Moral e da Legislação" que:

O termo utilidade designa aquela propriedade existente em qualquer coisa, propriedade em virtude da qual o objeto tende a produzir ou proporcionar benefício, vantagem, prazer, bem ou felicidade (tudo isso no caso presente, se reduz a mesma coisa), ou (o que novamente equivale a mesma coisa) a impedir que aconteça o dano, a dor, ou a infelicidade para a parte cujo interesse está em pauta; se esta parte for a comunidade em geral, tratar-se-á da felicidade da comunidade, ao passo que, em se tratando de um indivíduo particular, estará em jogo a felicidade do mencionado indivíduo. (Bentham, 1789, p. 05).

$\mathrm{Na}$ investigação, distante do estabelecimento de críticas e ou considerações sobre as condições axiológicas e eventuais cálculos hedonísticos para a proposição benthaniana do princípio de utilidade, a grafia da referência se fez conforme sugerido em Caillé (2001), em razão do encontro nas proposições benthanianas "ao que oficialmente se designa como utilitarismo" (Caillé, 2001, p. 39) embora tal designação seja reconhecida como insuficiente e Barbarói, Santa Cruz do Sul, n.53, p.<117-140>,jan./jun. 2019 
também em sua redução ao sujeito como ator e vinculação da utilidade de dado objeto a ação do sujeito.

Mediante a um rascunho referencial remissivo para a utilidade / útil e a início de reflexão de componente funcional, outro elemento foi considerado. Na proposição tomada a termo como viés reflexivo, há a ponderação castoriadiana de a instituição manter-se como rede simbólica socialmente sancionada provocando ao simbólico a figuração em elemento continente ao movimento de imersão investigativa, também considerando que: "As instituições formam uma rede simbólica mas essa rede, por definição, remete a algo que não o simbolismo" (Castoriadis 1975 p. 165), a eleição - adoção de símbolos, elementos materiais ou categorias à apreensão de componente funcional indicou o que pontuamos como pragmática de superfície.

Assim, ao propormos como hipótese uma dupla gravitação ao componente funcional instituinte, possuindo movimentos à sua grafia em elementos externos e internos a própria instituição, necessitávamos propor para a sua percepção na escola estadual de Igaraí a mesma dupla gravitação, fazendo da escola objeto interpenetrado e ineterpenetrante, espaço movediço com momentos em potencial sincronia e diacronia aos movimentos externos e internos, com principal atenção aos de seu entrono.

Neste sentido, o distrito de Igaraí se presentifica na escola e também a escola no distrito, acarretando para a possibilidade de apreensão e leitura de alguns elementos com potencial significante para a escola, a tentativa de leitura de alguns elementos com potencial significante ao distrito. Assim, interpenetração escola-distrito-escola não indica a ausência de algumas fronteiras / limites entre ambos, erigidas ou destacadas em momentos ou pontos de tensão na interpenetração. Neste aspecto a comunidade como conceito e eventual categoria adveio em razão das próprias limitações da construção da grafia. $\mathrm{Na}$ necessidade de uma referência remissiva mais ampla, acatamos a sugestão de Leeds e Leeds (1977) para o olhar ao distrito e escola, quando propõem o termo localidade e noções para estruturas supralocais.

\footnotetext{
O termo "localidade", todavia, refere-se, no contexto das distribuições geográficas humanas, aos loci de organização visivelmente distintos, caracterizados por coisas como um agregado de pessoas mais ou menos permanente ou um agregado de casas, geralmente incluindo e cercadas por espaços relativamente vazios, embora não necessariamente sem utilização. (...) Subáreas visivelmente distintas de uma cidade, nitidamente delimitada como invadida por um conjunto de posseiros, o conjunto de uma catedral e seus anexos também se enquadram nesta definição. Não importa quão simples seja um lócus, é também uma localidade segundo a definição dada. (Leeds e Leeds, 1977, p. 31 e32).
}

A adoção da localidade neste sentido propõe como marca esta se constituir em "pontos nodais de interação" indicando nestes: 


\begin{abstract}
...os pontos de maior densidade e mais ampla variedade de categorias de comportamento na área, mas não possuem necessariamente um conjunto exaustivo de categorias de comportamento (...) Assim, o uso do termo localidade não nos obriga a postular uma unidade mínima ou máxima de organização como a "comunidade" nem a discutir seu status ontológico. Precisamos apenas desenvolver instrumentos adequados e relevantes para lidar com sua descrição empírica. (Leeds e Leeds, 1977, p. 32).
\end{abstract}

Os autores (Leeds e Leeds, 1977) seguem apontando a extrema flexibilidade e fluidez adaptativa dos sujeitos nas organizações destas localidades e uma gama quase infinita de respostas para as formas de interação interna e externa, limitadas pela "extensão do total disponível de recursos, de terra, material, pessoal e finanças". (Leeds e Leeds, 1977 p. 34). De posse destas marcas pudemos partir à reflexão da escola também grafar-se como "lócus" / localidade e ao mesmo passo, como uma estrutura supralocal em atividade no distrito. Aqui, as estruturas supralocais referem-se:

\begin{abstract}
a organismos sociais para cujos princípios organizacionais qualquer conjunto dado de condições locais e ecológicas é irrelevante ou seja, em seus princípios fundamentais de ação, as estruturas supralocais confrontam qualquer localidade, qualquer subunidade sócio-geográfica do sistema total ou suas subdivisões, com normas ou instrumentos [uniformes e generalizados, organizacionais e operacionais]. A expressão "Instituições Supralocais" refere-se a princípios e modos de operação de estruturas supralocais. Qualquer estrutura cuja formação não seja governada por , ou relacionada a, uma dada localidade e que confronta várias localidades de maneira idêntica, é uma estrutura supralocal, operando com instituições supralocais. (Leeds e Leeds, 1977, p. 39).
\end{abstract}

\title{
O Distrito - documentos
}

Quanto a material bibliográfico sobre o distrito de Igaraí, o que fora encontrado dá-se em referências breves e limitam-se como exemplo, ao aspecto da proximidade do distrito a Minas Gerais em ocasião da Revolução de Trinta e Dois (Paladini, 1995, p. 52 e Freitas 1947, p. 240), a existência do distrito de paz, eleição de juízes de paz e a contribuição estatística do distrito ao incremento da agricultura local (Freitas, 1947, pag. 334, 139 e 170).

Na busca nos autos da Câmara Municipal de Mococa com a referência Igaraí, encontramos 263 requerimentos, 01 projeto de lei e 01 projeto de lei complementar no período compreendido entre janeiro de 2008 à agosto de 2012.

Neste universo de questões cotidianas, alguns requerimentos chamaram a atenção pela frequência temática e foram classificados para efeitos de análise em grupos distintos. Os grupos foram organizados em acordo com a própria sugestão temática dos requerimentos constituindo: Grupo 1 - Segurança; Grupo 2 - Agências Bancárias; Grupo 3 - Telefonia; Grupo 4 Transportes; Grupo 5 - Saúde; Grupo 6 - Emancipação. 
A exceção para a condição de frequência nesta conformação de grupos fez-se junto ao Grupo 06 - Emancipação, constituído exclusivamente a partir da peculiaridade temática, sob a expectativa da grafia de alguma expressão mais clara de distensões entre o poder público municipal e a população do distrito de Igaraí. Neste caso específico, os requerimentos $n^{\circ} 1423$, 1424, 1425 e 1426/2011, não são apresentados por representante residente e tratam da "independência" dos dois distritos do município de Mococa.

Deste modo, na leitura dos requerimentos apresentados à Câmara Municipal o encontrado nas justificativas, tanto dos requerimentos quanto das devolutivas que tivemos acesso, apontava questões do distrito que sugeriam uma interconexão viciosa e indicam ainda, mesmo que timidamente, para que quadros de ausência se justifiquem e se legitimem.

Isto, dentro de um exercício de raciocínio amparado em uma lógica perversa e não necessariamente em constatações de fato, abria margem ao estabelecimento de conexões entre a falta de policiamento inviabilizar a existência de postos bancários e expansão de telefonia fixa, enquanto que a ausência de postos bancários em conjunto com as condições locais de acesso à saúde exigirem redimensionamento nos horários e itinerários do transporte coletivo. Em sentido inverso e em extensões ao absurdo, havia a possibilidade de grafar na resolução das condições de transporte do distrito à sede do município, ou no seu policiamento, as suas grandes panaceias.

A conformação das ausências ou morosidades registradas nos requerimentos apresentadas na Câmara Municipal ou ainda na história "oficial" do município podem municiar elementos de legitimação a prováveis marcas de abandono. Neste sentido, principalmente a ausência de policiamento ostensivo, de posto ou distrito policial na localidade, amplia espaços de re-significação da insegurança em abandono e de abandono em possibilidade de descaso do poder público, em geral, à população do distrito.

Neste panorama de busca a elementos e marcas à leitura e percepção do distrito frente ao até então registrado ou ausente, houve a possibilidade da grafia imaginária do distrito manter-se, contraditoriamente, sob bases de desamparo. Cabe aqui retomar o imaginário, tomado em acordo com Castoriadis (1995), quando este propõe que:

O imaginário de que falo não é imagem de. É criação incessante e essencialmente indeterminada (social-histórica e psíquica) de figuras / formas / imagens a partir das quais somente é possível falar-se de "alguma coisa." Aquilo que denominamos "realidade" e "racionalidade" são seus produtos (Castoriadis, 1995, p. 13). 
O amparo aqui apontaria outras formas de visibilidade e conciliação entre o distrito e o poder público municipal, grafaria outras marcas e regras ao jogo de relacionamento entre ambos, caracterizando-o como, em acordo com Sennett (2011):

\footnotetext{
... uma constante nas questões humanas; as modernas burocracias ocidentais não o transcenderam, mas o enterraram, de tal sorte que ele se torna mais cômodo quando é impessoal, e negociado cara a cara, não por declarações como "Você precisa me ajudar", mas por jogos mais velados no qual os subalternos esperam conseguir a proteção dos superiores (Sennett, 2001, p. 237).
}

A posse destes indicativos não nos autoriza a caracterizar o distrito como um corpo cívico, espaço de destinos compartilhados (Sennett, 2001, p. 371 e 372), atrelando o fardo da vida dos habitantes ao futuro do distrito. Mesmo os requerimentos que comportam a solicitação de emancipação do distrito não figuravam como reflexo de um imaginário partilhado e instituinte de práticas e ações cotidianas. Neste caminho, se considerarmos em acordo com Bauman (2001) que:

$\mathrm{O}$ "comunitarismo" ocorre mais naturalmente às pessoas que tiveram negado o direito à assimilação. Tiveram negada a escolha - procurar escolha na suposta "fraternidade" do grupo é a sua única opção (Bauman 2001, p. 87),

Ainda nos é cerceada, pois as condições de desamparo, se efetivas, não se constituem como negação a assimilação ou em vínculo, a tal ponto, da fraternidade tornar-se a única escolha desta população.

Pudemos sim naquele momento grafar como hipótese e exercício para a reflexão da possibilidade de um ressentimento acomodado contra as injustiças padecidas, pontuando momentos de solidarização e distensão entre os habitantes. Neste aspecto, as prováveis injustiças padecidas não catalisariam rebeliões na população em razão de suas condições anteriores (Bauman, 2001, p. 75), mas sim a sobremarcariam caracteristicamente em distinção "invejosa" do seu entorno.

\section{O Distrito: mais traços}

Elencar ou agrupar os fatores de ausência, precariedade, distância e o reconhecimento do distrito como espaço privilegiado à elaboração da subjetividade para seus moradores não se fazia suficiente, a exemplo de mosaico, para a constituição de uma paisagem local clara, distinta e apreensível a observador externo sobre o que pode ser rascunhado como o distrito. A possibilidade de um esboço, mesmo de uma lavra lascada do distrito exigiu um jogo de concatenar cujas peças lançadas eram móveis e não se assemelhavam nas formas, mas se interpenetravam em conteúdos produzindo ao resultado de qualquer junção sempre um 
deslocamento em paralaxe. Neste sentido, aquilo que se apresenta sobre o distrito é sempre superfície.

...porque lá eles não tem noção de lei, se acontece alguma coisa eles tem que vir até Mococa pra registrar um boletim de ocorrência, pra formalizar aquela ocorrência e tal. Então eles não vem. Como eles não vem, eles também não tem a dimensão da consequência daquele ato, então a lei é feita ali... Por eles mesmos. Se entendem, resolvem e é aquilo ali... (Gestora 1).

...uma vez que o lugar é pequeno, existe essa união. É um bem muito grande essa união, você fala bom dia as vezes pras pessoas todo dia, né?, outros dias você encontra elas no teu lazer, você encontra elas no mercado, você tá indo pro trabalho encontra elas. Isso ai é, tem uma colaboração muito grande pra que a longa amizade, vem uma palavra bem "pertinha" da amizade que chama intimidade. Você passa a ser intimo da pessoa, agente passa a falar pra aquelas pessoas coisa que vem de dentro da nossa casa e eles também passa a contar, então a gente passa a cumprir aquela parte, quer dizer, a gente tá feliz porque eles estão feliz, ou a gente tá triste porque eles estão triste. (...) Então se uma pessoa vem pra cá, pra Igaraí, ele chegou aqui agora, ele vai começar a morar aqui, todo mundo sabe que ele chegou agora, todo mundo sabe que ele acabou de chegar, e aquela pessoa ele vai vim pra cá e... muito difícil ele trazer alguma coisa de fora... a força maior é ele aprender o que nos temos aqui. Então ele vai ver todo mundo falando bom dia pra ele, todo mundo falando como vai, então aquela pessoa vai dizer meu deus eu nunca vi isso. De repente acontece o que aconteceu comigo, eu pensei que ia morar um ano aqui... olha eu tô a vida toda aqui. (Morador e ex-membro da associação de pais e mestres).

Da superfície aqui sugerida, as impossibilidades de caracterização estrita do distrito como comunidade ou gueto e ainda, de caracterização como espaço cívico como anteriormente mencionado, são mantidas. O relevo de ausência ou precariedade apontado por todos os atores fazia-se marca característica e promotora de arranjos internos inerentes a própria marca. Contraditoriamente, a grafia desta marca configurava-se a elemento distintivo ou com aspecto identitário para observador externo que o classifica, ou no caso, àquele não filiado ao distrito e que por ele transita.

...falta muita coisa pra eles; atividade cultural, atividades esportivas que poderiam envolver a população, principalmente a população mais jovem e não tem nada disso. Então o que eles fazem? Eles bebem muito né. (Doador do terreno).

Assim, a produção de arranjos internos para a tentativa de supressão ou minimização das precariedades não denotava, ou eram denotadas, estritamente de complexos filiativos ou identitários entre os diversos atores do distrito, mas de necessidades pontuais momentaneamente compartilhadas.

Neste caso e a título de exemplos, a dificuldade de deslocamento, o pequeno número de horários do transporte coletivo promove a organização de caronas, a adoção de veículos de aluguel de forma compartilhada, o fretamento de transporte coletivo para idas ao trabalho. A ausência de policiamento ostensivo produz a contratação "coletiva" de empresa privada para segurança patrimonial e ronda noturna. A suspensão ao termo coletiva decorre de eventual custo de empreendimento, que mesmo dividido, não é passível a toda população. 
A distância do poder público, o desejo de amparo registrado nos documentos confundese ao descrédito sobre sua eventual presença, sentida como reflexo de outros interesses que não a atenção para a localidade. Isto foi possível notar quando da promoção do "mutirão da saúde" e a relativa baixa participação da população aos espaços preventivos. A constante circulação de pessoas junto ao local não indicava efetivamente a participação aos pontos de atendimento.

A não participação de parcela da população local ao uso efetivo de atendimentos para a saúde momentaneamente disponíveis abriu caminho à reflexão do poder público local também funcionar como estrutura supralocal, denotando reflexos aos demais equipamentos municipais constituídos, fragilizando ou fraturando a possível / potencial legitimidade das instâncias municipais ali existentes pela população local.

Uma vez mencionada a supralocalidade voltamos à referência de Leeds e Leeds (1978) sobre os "objetivos" do Estado:

\begin{abstract}
Os objetivos do Estado são dois: primeiro, a coordenação pública, administração e manutenção da ordem em toda a sociedade, e segundo, sua própria manutenção como um grupo de interesse especial, geralmente uma classe dominante e seus representantes. O primeiro objetivo público do Estado, isto é, a supervisão dos interesses da sociedade, é em si mesmo ambivalente, porque frequentemente o interesse da sociedade pode corresponder, por diversas razões, ao interesse privado do Estado em se manter.(...) Esta dupla dualidade das finalidades do Estado, imprime em suas relações com as localidades uma dualidade, ou talvez até melhor, uma polaridade correspondente. As duas finalidades de polaridade englobam, por um lado, relações cooperativas precisas surgidas de interesses comums e por outro, antagonismos precisos e lutas. Estágios intermediários envolvem cooperações mais ambíguas provenientes de interesses diferentes que podem ser alcançados por meios comuns; relações bastante neutras de coexistência ambivalente ou autonomia generalizada; resistência sem antagonismo aberto, e assim por diante. (Leeds e Leeds, 1978, pag. 40).
\end{abstract}

Pudemos aqui retomar a hipótese da existência de um ressentimento acomodado contra as injustiças padecidas, pontuando momentos de solidarização e distensão entre os habitantes junto as formas de enfrentamento das questões do distrito, porém, para não contribuir com a legitimação do quadro de ausência, o esboço do distrito pode sugerir, indistintamente, uma proto-comunidade com contraditório potencial à gueto ou, um proto-gueto com contraditório potencial à comunidade.

A indistinção potencial contraditória, lembrando Bauman (2001), quando este posiciona que "o gueto é a impossibilidade de comunidade", faz-se em razão dos elementos existentes no distrito e suas possibilidades de movimento, a possibilidade de construção de um vir-a-ser em permanência ou um devir qualquer outro.

A territorialidade grafa ainda uma tênue fronteira entre o "dentro" e o "fora", aquele espaço próprio, íntimo, passível à partilha cotidiana em comunicação das coisas da casa 
somente aos de "dentro". Subvertendo Bauman (2001), quando este comenta Hannig Bach, por este se referir a "conjuntos grandes, densos e permanentes de seres humanos heterogêneos em circulação", podemos indicar os de fora sempre como superfície aos de dentro e o mesmo inversamente.

\begin{abstract}
... tendemos a nos tornar superfícies para os outros - pela simples razão que esta é a única coisa que uma pessoa pode notar no espaço urbano com grande quantidade de estranhos. O que vemos "na superfície" é a única medida disponível para avaliar um estranho. $\mathrm{O}$ que vemos pode prometer prazer, mas também pode anunciar perigo; quando apenas superfícies se encontram, (e sempre "de passagem") há poucas chances de negociar e descobrir o que é o quê. E a arte de viver numa multidão de estranhos impede que esta chance se materialize - deter o encontro antes que ele mergulhe além da superfície é o mais comum dos estratagemas. (Bauman, 2001, p. 131 e 132).
\end{abstract}

Neste quadro potencial, sem a possibilidade de mensuração sobre as formas de incorporação deste potencial pela população, a imagem de "não-lugar", figurativamente, acaba sendo sugerida:

... naquele tempo a jovem guarda estava na crista da onda. O Roberto Carlos ia fazer um show, não sei se era em São Jose do Rio Pardo. Ele se perdeu e passou dentro de Igaraí... "Cê" quer coisa mais legal? Que a gente ficava na jovem guarda das 7, do canal 7, né? Que era as quatro e meia da tarde, não perdia um domingo. Aprendi a tocar violão com o Roberto Carlos naquele programa... Eu lembro que falaram: "nossa, ele tá perdido e passou dentro de Igaraí!" Então isso ai foi né, o grande acontecimento do século lá pra Igaraí. (Ex-moradora doadora do terreno).

Assim:

compartilhar o estigma e a humilhação pública não faz irmãos os sofredores; antes alimenta o escárnio, o desprezo e o ódio. Uma pessoa estigmatizada pode gostar ou não de outra portadora de estigma, os indivíduos estigmatizados podem viver em paz ou em guerra entre si - mas algo que provavelmente não acontecerá é que desenvolvam respeito mútuo. "Os outros como eu" significa os outros como eu tenho repetidamente afirmado e mostrado ser; "parecer mais com eles" significa ser mais indigno do que já sou. (Bauman, 2001, p. 110).

E por extensão, este recuo a potencial estigma abre sim horizonte a lampejo de gueto, a convívio constantemente fraturado por fantasma estigma partilhado como devir possível.

\title{
Impressões de escola
}

A escola, que abriga o ensino fundamental e médio, atualmente opera em três períodos letivos e comportava em seus quadros, em acordo com informações prestadas pela direção da unidade escolar ${ }^{1}$, vinte e sete professores ativos. Neste universo de vinte e sete professores ativos, nove professores eram efetivos e com sede na própria unidade escolar.

\footnotetext{
${ }^{1}$ Informações Apresentadas em ofício 053/2012 de 14 de maio de 2012. 
Em acordo com planos de gestão escolar dos quadriênios 2007-2010 e 2011-2014, com estrutura, objetivos e características da escola e comunidade transferidas em "facsímile" de um plano a outro, a escola possui uma área construída de $2.000 \mathrm{~m}^{2} ; 10$ salas de aula; uma sala ambiente para informática; uma sala de leitura, uma quadra e um acervo de 7.800 livros, incluso neste montante livros didáticos, paradidáticos e material apostilado recebido do Estado.

Os referidos planos grafam a principal clientela na faixa etária de 07 a 18 anos, um corpo discente de baixa renda e composto aproximadamente por $50 \%$ de discentes moradores da zona rural. Indicam ainda a dificuldade ao acesso a outros equipamentos culturais, registrando:

... a localidade não tem nada a oferecer e os pais não tem condições de oferecer viagens e passeios para as crianças, pois só folgam no domingo e torna-se inviável pela condição financeira dos pais. (PPP - Projeto Político Pedagógico 2011-2014, p. $09)$.

Os planos registram unidade escolar vizinha mais próxima na malha urbana do município a uma distância de vinte e oito quilômetros. Tomando o plano de gestão para o quadriênio 2011-2014, por este em vigência e trazer consigo reproduções textuais do plano anterior, além de análise das propostas pedagógicas contidas no plano de gestão do quadriênio 2007-2010, encontramos os objetivos em relação às modalidades de ensino como segue:

\footnotetext{
A expectativa da escola para o nosso aluno, ao concluir o ensino fundamental, é que apresente bons hábitos comportamentais, que seja autor de seu conhecimento, tenha senso de autocrítica, seja curioso e interessado, tenha senso crítico desenvolvido e que seja informado e pronto para enfrentar a realidade dentro e fora da escola. (PPP - PPP - Projeto Político Pedagógico 2011-2014, p. 29).

... o perfil do nosso aluno que a escola deseja é que o aluno consiga aprofundar seus conhecimentos adquiridos no ensino fundamental, que tenha desenvolvido razoavelmente a sua comunicação, que apresente qualificação mínima exigida pelo mercado de trabalho, preparado para exercer sua cidadania com autonomia e que esteja apto a disputar vaga no ensino superior. (PPP - Projeto Político Pedagógico 2011-2014, p. 30. sobre o ensino médio).
}

A relação com a comunidade também é grafada no projeto político pedagógico. Registro junto a página 33 aponta que: "a comunidade é bastante participativa e tem um sentimento de posse pela escola. (...) e que nada é feito ou trabalhado sem a discussão com toda a comunidade escolar".

Além dos Projetos Políticos Pedagógicos, foram observadas 39 atas com reuniões com pais em período compreendido de 2008 a 2012, seguindo na conformação temática de grupos e desconsiderando um grupo específico sobre aproveitamento escolar, pano de fundo presente direta ou indiretamente a todas as atas. Sob este pano de fundo, considerando também que em razão de seu teor e ou proposta de pauta uma mesma ata poder comportar mais de um tema, 
buscamos ao longo do recorte temáticas que pudessem indicar os principais vetores de diálogo da escola com os pais a partir de seu registro e recorrência. Compomos assim três grupos temáticos: Frequência de Alunos; Questões Comportamentais e Uso de Material Didático.

Os documentos observados tencionam a percepção de uma arquitetura para processos com aspectos autonomizados, parecendo figurar à escola e seus autores como legítimos proponentes dos ritos ali registrados. Isto observado, podemos considerar que ao passo que alguns elementos com características estruturantes da escola são exteriores a esta, obrigatoriedade dos alunos à presença como exemplo, as formas de leitura e elaboração de mecanismos às aplicações e desenvolvimentos são internos e parecem reflexos de uma lógica inerente à própria escola e suas características particulares.

A possibilidade de leitura a uma pragmática de superfície, codificada nas expectativas da escola aos perfis de egressos grafados nos Projetos Políticos Pedagógicos, não nos garantiam a suficiência a assertivas sobre a existência de uma burocracia amparada estritamente na sua finalidade, da escola, legitimada por legalidade externa e interna promotora, por si, de racionalidade às ações.

Os registros em atas sugeriam a existência do rito burocrático partilhado a diferentes atores significativos ao cotidiano escolar, porém não garantiam ou traçavam, salvo episodicamente e de maneira tímida, as formas de incorporação e representação do rito e sua suposta racionalidade por estes atores. A partir das atas, a própria percepção de rito burocrático pareceu amparar-se na estada dos pais junto da escola, não apontando os registros para qualquer aspecto de legitimidade ou ilegitimidade sobre os códigos operatórios, ou ainda do rito proposto pelos gestores aos pais presentes.

Também despertou a atenção, em atas de reunião do Conselho de Escola, a recorrência do registro sobre negativa de professores alocados na unidade de ensino para a substituição temporária de vice-diretor. Os registros não são suficientes para apontar uma possível depreciação da autoridade, cargo ou função partida dos professores. Em sentido inverso, não podemos também afirmar que as constantes recusas, mesmo para a ocupação temporária, possam se pautar na existência de construtos de autoridade estabelecidos e sedimentados entre direção e corpo docente que transcendem a investidura no cargo / função, embora como lembra Silva (2001):

Nas organizações escolares em geral, o que se observa frequentemente é a legitimação da autoridade baseada no cargo ocupado. No caso do professor, tem sido o diploma do qual ele é portador que o habilita a estar no papel de detentor de um saber; no caso da direção da escola, a autoridade é legitimada também pelo cargo e pela responsabilidade legal que o acompanha. Na prática, no entanto, observa-se que há, e cada vez mais, uma resistência ao reconhecimento dessa autoridade, tanto por parte

Barbarói, Santa Cruz do Sul, n.53, p.<117-14O>,jan./jun. 2019 
dos alunos em relação aos professores, quanto por parte dos professores em relação à direção (Silva, 2001, p. 133).

Podemos seguir e mencionar a possibilidade não só de uma pragmática de superfície, mas de funcionalidades diacrônicas, convergindo ainda às reflexões de Silva (2001), quando esta aponta para a diversidade de elementos na composição da cultura organizacional escolar e esta cultura, como resultado de processo interativo cujos símbolos e significados são constantemente reinterpretados à medida que a realidade se constrói, pontuando ainda que:

A compreensão da cultura da escola como um processo dinâmico e negociado entre os diferentes atores do processo pedagógico permite uma compreensão mais aprofundada da contribuição de tais atores na construção dos valores, crenças e princípios, assim como nas ações que se processam na vida cotidiana (Silva, 2001, p. 129).

Aqui mais uma vez convergimos às inquietações promotoras da reflexão. A base de registros, o conjunto documental, não se faz suficiente a elaboração de esboço sobre a funcionalidade, ou o(s) componente(s) funcional(is) da escola objeto. Estes registros indicam relações amparadas em elementos potencialmente instituintes, internos e externos, norteadores de ações para uma grafia do cotidiano escolar.

\section{Ecos de escola}

O rascunho da escola como lugar remeteu à possibilidade de reflexão sobre formas ou nós de interação entre os atores que, sob múltiplas circunstâncias, para lá convergiam. Esta convergência abriu novamente a perspectiva de percepção de funcionalidades diacrônicas ao passo em que condicionavam, porém não determinavam em sentido estrito, arquiteturas de elementos / redes simbólicas componentes de sedimentos da instituição do lugar-escola e mediadoras às próprias funcionalidades.

Neste sentido podemos mencionar que:

As redes simbólica e funcional mesclam-se, então, na medida em que se estabelecem símbolos capazes de corresponder ao funcional e o funcional depende do simbólico para existir. Desse modo, uma realidade funcional que pretende ser "lógica" e uma dimensão simbólica (imaginário efetivo) a ela relacionada buscam "dominar" os sujeitos inserindo-os no universo institucional instituído. A rede simbólica ${ }^{2}$ da escola, enquanto construção universal sobre o que a escola é ou deve ser, sobre sua função ou modo de funcionar, bem como sua organizaçã $o^{3}$, estrutura singular estabelecida em correspondência a tais crenças, situam-se no que chamamos de polo instituído da escola. (Nadal, 2008, p. 68)

\footnotetext{
${ }^{2}$ Grifo da Nadal.

${ }^{3}$ Idem.
} 
Desse modo podemos ponderar que o lugar-escola para além de unidade abstrata ou edifício material presentifica-se corporeamente também como símbolo, dando margens a carpintarias sobre o ser, não-ser e o devir escola por todos aqueles que a encontram.

Isto pode ser notado, a exemplo, em encontro da narrativa da Gestora 2, quando do sentimento de posse de parcela de seus funcionários as coisas da escola:

... outra dificuldade que eu vejo é que as pessoas se sintam um pouco donas da escola, as pessoas que trabalham aqui né, sentem um pouco donas da escola, como se pertencesse a eles, como se as coisas pertencessem a eles e não a comunidade como um todo. Assim, tem uma mesa de ping-pong não, não vai por se não vai estragar, mais é pro aluno, tem que colocar, quem tem que usar é o aluno... (Gestora 2).

A tentativa do estabelecimento de possessões, de quintais à estada dá margem a marcas sobre a possibilidade de construções a funcionalidades diacrônicas condicionando a elaboração de marcas ao contato, marcas / indicações imprecisas, porém vetores de negociação ao contato pretendido sustentando elementos distintivos à elaboração de pragmáticas de superfície:

... e eu ate levei uma bronca da minha dirigente na época, que era a (...); que era a dirigente regional. Como atrair as pessoas para escola? Lá nas primeiras reuniões de pais eram pouquíssimos, pouquíssimos..., Como que a gente vai fazer?... Então, não sei se a GESTORA 3 já te contou isso? Agente conseguiu montar cestas básicas... A gente vai ter reuniões de pais, o pai que vier na reunião, na entrada vai receber um numero e depois que acabar a reunião vai fazer o sorteio das cestas básicas... Mas lotou o pátio da escola, "cê" entendeu? (Gestora 1).

O estabelecimento de marcas / vetores ao contato pode revelar movimentos contraditórios na elaboração das próprias marcas e na movimentação a contar das marcas tangidas. Assim podemos encontrar trecho da narrativa da ex-moradora e doadora do terreno sobre a constituição do ginásio, momento em que faz menção a professores:

... professor nenhum queria ir pra lá. Era uma luta danada pra conseguir professor, né? E foi justamente depois de ter criado o ginásio ainda funcionando nas duas salas, que foi na época do (...) que foi ele que conseguiu a construção lá, é que pensou-se em fazer o prédio novo porque não estava comportando mais. Porque daí já teve a primeira série, a segunda série e foi indo até a quarta série. (Ex-moradora doadora do terreno).

Propor a escola como um intralugar no distrito, mais uma vez remonta a possibilidade de reflexão da escola como espaço supralocal, espécie de intralugar que modifica a constituição dos "de dentro da escola" tensionando a relação de residência ou não residência no distrito como marco à eventuais grafias sobre escola.

Deste modo, buscar perceber o lugar-escola apresentando-se "através de sua dimensão instituída - como uma realidade presente a qual - através de sua dimensão instituinte - pode assumir a característica de transformação mais ou menos constante, avançando a partir do que está instituído" (Nadal, 2008, p. 71) e mantendo-se como si a partir de deslocamentos do Barbarói, Santa Cruz do Sul, n.53, p.<117-14O>,jan./jun. 2019 
instituído por e para si, provoca nos encontros e interpenetrações movimentos emaranhados, aparentemente contraditórios e confusos, porém pertencentes e legitimados em fazeres à manutenção e ou busca de manutenção do imaginado enquanto lugar-escola e funções dos atores / autores, pelos próprios atores / autores ali em alguma estada.

O emaranhado aqui figura como reflexo de ações à "constituição de indivíduos sociais, que só são tais e só podem funcionar como tais, na medida em que sua socialização "informa" as manifestações de sua imaginação radical" (Castoriadis, 1975) para outros enquanto da percepção de algum vínculo - mesmo precário - com o lugar-escola.

Você percebe assim: tudo que faz em obra, que pinta, que aparece eles gostam mas, nem sempre esse é o melhor, às vezes é melhor você investir no lado pedagógico que no lado da estrutura... mas eles vêm... Você percebe o que mostra... o que dá é a obra né? A obra de pintar, fazer muro... (Gestora 2).

Assim, a necessidade de intervenções físicas no prédio da escola que parece indicar momento de abertura a maior encontro entre escola e população local, registra também marcas à apropriação do objeto escola pela população local. Este possível momento de abertura à maior encontro e apropriação é grafado, como exemplo, na fala de Morador Ex-membro da APM ao pontuar que durante e após as intervenções “...a escola começou a brilhar, a ficar bem e começou a ter um aumento nas reuniões..."

A abertura a maior encontro entre população local e escola remete também a possibilidades de construção de variados complexos "filiativos" entre interventores e objeto em intervenção / interferido. Tomando por metáfora o desenvolvimento das cidades modernas que denunciaram e tornaram falsas as ideologias nacionalistas e revolucionárias sobre um só destino aos povos (Sennett, 1994), a estada no lugar-escola parece ao mesmo passo denunciar e sustentar a premissa falsa de manter-se como espaço necessário de aproximação e compartilhamento de destinos. Desta forma se "pode-se dizer que as prisões são guetos com muros e os guetos prisões sem muros" (Bauman, 2001, pag. 109), o lugar-escola constitui-se entre ambos, distinguindo-se destes por não possuir todas as rotas de fuga interditadas, mas obstaculizadas e as condições para a eventual permanência / estada não ser tomada, necessariamente, como potencial estigma.

Assim, para aquele em estada no lugar-escola há a tentativa de feitura neste espaço, de sua possessão e cercamento de eventual quintal, de exercícios à constituição de guetos individuais e às avessas. Neste aspecto podemos encontrar Sennett (1994), em proporções devidas, quando observa as transformações em Nova York:

\footnotetext{
${ }^{4}$ Grifo do Castoriadis.

Barbarói, Santa Cruz do Sul, n.53, p.<117-14O>,jan./jun. 2019
} 
... houve várias tentativas de conferir às vidas segregadas uma personalidade coletiva honrada. Tais esforços ocorreram por toda a parte, entre novos imigrantes e negros, judeus pobres e outras etnias relegadas. Reviver o amor-próprio do gueto implicava em voltar-se para dentro do espaço e da mente. A atividade dos embriões comunitários concentrou-se na busca de uma distinção comum, através da ocupação de prédios que definissem o território próprio do grupo, mais do que em fazer contato com os diferentes. (Sennett, 1994, p. 370).

Na ocupação do lugar-escola o homogeneizado está fora de seus muros, sua estada é chamada e consentida, sua permanência no local demanda algum aprendizado ou adoção das regras internas para uma estada mais fluida. $\mathrm{O}$ grupo interno, por sua vez, faz da posse de certa "cultura escolar" herdada e em constante (re)produção muros a fortaleza sitiada e,

numa fortaleza sitiada os habitantes tem que manifestar diariamente sua lealdade inquebrantável e abster-se de quaisquer relações cordiais com estranhos. A “defesa da comunidade" ${ }^{" 5}$ tem que ter precedência sobre todos os outros compromissos. (Bauman 2001, pag. 127).

A lealdade em questão desloca-se entre o amor-próprio do gueto mantido em buscas de elementos legitimadores à estada / ocupação, ao instituído como específico do lugar-escola, mantido em constante exercício e tentativa de presentificação e aproximação aos objetivos e funcionalidades declaradas e (re)conhecidas em registros internos e externos, grafado em práticas que correspondam "a uma necessidade funcional - "formar crianças e jovens através da aprendizagem, da interpretação, produção, resolução de problemas...” (Nadal, 2008, p. 68), e para um outro habitante do lugar-escola enquanto outro em estada e em certa medida percebido como do grupo, tanto pela estada como pelas tentativas de exercício à manutenção da funcionalidade da escola.

\section{Outras considerações}

A tentativa da percepção de elementos com potencial significante e possíveis vetores à compreensão de componente(s) funcional(ais) de uma instituição / escola, nos remeteu à localidades interpenetradas, subsidiárias e sobrerreferenciadas, erigidas a próprios elementos significantes.

Mencionar que o distrito se presentifica na escola e a escola se institui também a partir do distrito que nela se presentifica, promovendo arranjos móveis e marcas precárias indicativas ao fazer ou não fazer para os atores em qualquer dimensão de "visita" na escola, parece redundar na obviedade do distrito se fazer vivo na escola.

\footnotetext{
${ }^{5}$ Grifo do Bauman.
}

Barbarói, Santa Cruz do Sul, n.53, p.<117-14O>,jan./jun. 2019 
A aparente obviedade parece validar também possibilidades de câmbio entre "sujeito" e "predicado" sem prejuízo de sentidos, provocando a impressão de sinonímia e reciprocidade à premissa: a escola se faz viva no distrito.

Distante de qualquer arremedo a exercício lógico maior ou menor, a atenção recai na eventual obviedade aparentar também que esta vida interpenetrada soe a vida integrada e, mesmo com relevos ou alguma heterogenia, mantenha-se sincrônica em sentidos por também algum reconhecimento a espécie de fim último ou co-utilidade partilhada.

Assim, considerando que a interpenetração não denota necessariamente integração, recuamos à outra possível obviedade cuja vida em nossa premissa inicial pode converte-se em cisão / fratura e, deste modo, promover a re-confecção da premissa em: o distrito cinde a escola; premissa também aparentemente válida.

Da mesma forma, o exercício anterior pode ser aplicado resultando na cisão soar a vida apartada e, mesmo com alguns momentos a certa aproximação ou homogenia entre atores e objetos, manter-se diacrônica em sentidos pela ausência de algum reconhecimento a espécie de fim último ou co-utilidade partilhada.

As extensões contraditoriamente não soam a absurdo, não fazem remissão a algum nãosenso basilar mutuamente excludente ou ainda, propõem alguma virtude mediana. As extensões apenas indicam dupla gravitação em órbitas irregulares no instituinte / instituído a componente(s) funcional(is) da escola denunciando sim a ausência de algum metro para a sua plena referência.

A denúncia de ausência de algum metro não retira por sua vez a possibilidade de apreensão de ecos, vozes e matizes que embora ímpares pelos arranjos entre sujeitos e objetos, reverberem a aparentemente mesmos, ou similares a outros conjuntos escola-comunidadeescola / comunidade-escola-comunidade, considerando a escola instituir-se também a partir de marcas externas, podendo ser apreendida como instância supralocal.

Desse modo, a instituição do lugar-escola como espaço de / para a diferença tensionando formas de experienciar o distrito e do distrito experienciar a escola parece transcender momentos de encontros formais entre parcela da população e escola, a exemplo em reuniões com pais.

Podemos aqui retomar Castoriadis (1975), ao considerar que "as instituições formam uma rede simbólica mas essa rede, por definição, remete a algo que não o simbolismo" (Castoriadis, 1975, p. 165), mas a possibilidade de elaboração / manutenção de pragmáticas de superfície não necessariamente sincrônicas a elementos significantes e indicadores "do que fazer", elaboradas / mantidas à medida que informam e constituem indivíduos sociais (Nadal, Barbarói, Santa Cruz do Sul, n.53, p.<117-14O>,jan./jun. 2019 
2008) que só podem funcionar enquanto tais a medida em que manifestam sua imaginação radical - dos indivíduos sociais - em aberturas à socialização.

Deste modo se a escola se institui / é instituída como "uma rede simbólica, socialmente sancionada, onde se combinam em proporções e em relações variáveis um componente funcional e um componente imaginário” (Castoriadis, 1975, p.159) e, internamente mantém-se em práticas ou exercícios à presentificação de marcos externos, sejam eles em atendimento a legislação / burocracia instituinte ou ainda como formas de conciliação / resistência sobre grafias a eventual utilidade dada localmente também instituinte.

O quintal apossado, invadido / ocupado parcial ou integralmente por aqueles que não são necessariamente da casa e que para a legitimação de sua estada redefinem simbolicamente o espaço ocupado, redefinição mantida também na elaboração / exercício de práticas distintivas, potencialmente delineadora do conjunto de atores em ocupação, alija em meio a estes processos de empossamento a então legitimidade para a estada neste mesmo quintal de parcela da população do distrito.

Tomando Sennett (2004), quando este reflete sobre a "escassez de respeito" e pontua que "em lugares em que há poucos recursos e a aprovação do mundo exterior está em falta, a honra social é frágil; ela precisa ser assegurada a cada dia" (Sennett, 2004, p.51) para posteriormente indicar três formas à conquista de respeito e destas:

\begin{abstract}
A terceira maneira de ganhar respeito é retribuir aos outros. Esta é talvez a fonte de estima mais universal, intemporal e profunda para o caráter de alguém. Como ocorre quando assistimos uma peça, podemos aplaudir o brilhantismo ou as exibições de capacidade; o príncipe de Maquiavel pode suscitar a homenagem dos submissos, mas nem o virtuoso, nem o tirano tocam os sentimentos dos outros da mesma forma que alguém que retribui algo a comunidade. A auto-suficiência também não é bastante para que se conquiste este tipo de estima, em última análise, o auto-suficiente não tem maiores consequências para os outros, uma vez que não há ligação mútua e nenhuma carência necessária dela. A troca é o princípio social de que anima o caráter de quem retribui a sociedade. (Sennett, 2004, p. 82).
\end{abstract}

Mesmo que o distrito não se constitua como gueto e não espere ou busque aprovação do mundo exterior, a escola ao provocar alijamentos mesmo que episódicos reduz vetores à troca com a população local.

O respeito a que Sennett (2004) menciona, como o autor mesmo traz, denota algum tipo de desigualdade e, neste sentido, a redução de vetores à troca abre possibilidade a leituras sobre alguma potencial autossuficiência do lugar-escola ao atendimento de suas demandas internas, repontuando-a como Estado presentificado no distrito ou ainda, alguma leitura depreciativa à demandas da população que o lugar-escola atende. 
Deste modo, mesmo que a utilidade declarada e assumida por si - escola - deflagradora de elaboração de ritos / rotinas legitimadoras de si seja potencialmente reconhecida e percebida como legítima pela população, os ritos / rotinas elaborados ou em elaboração podem não sê-lo de forma integral, desencadeando duplo movimento aparentemente contraditório de reconhecimento e deslegitimação aos exercícios pelo lugar-escola propostos ou praticados.

O mesmo resultado pode também advir da eventual utilidade declarada e assumida por si - escola - não ser plenamente reconhecida como legítima por não partilhada e negociada com a população local, provocando na elaboração / adoção de práticas para a sua presentificação pontos de tensão e momentos de afastamento entre escola e população local.

Neste aspecto podemos reencontrar Castoriadis (1975) e mencionar que ao passo que a escola do distrito de Igaraí se guetifica, se aliena, isto considerando que a alienação

\footnotetext{
"é a autonomização e a dominância do momento imaginário na instituição que propicia a autonomização e dominância da instituição relativamente à sociedade. Esta autonomização da instituição exprime-se e encarna-se na materialidade da vida social, mas supõe sempre também que a sociedade vive suas relações com suas instituições à maneira do imaginário, ou seja, não reconhece no imaginário das instituições seu próprio produto." (Castoriadis, 1975, p. 159 e 160)
}

e ponderar que do atendimento de Arendt, (1954) sobre cumprirmos um divórcio entre educação e outras esferas da vida, aqui a escola - não a educação - encontra-se em momentos de divórcio com o distrito, cujas partes mesmo que intencionalmente de boa fé conservam-se potencialmente como litigantes.

\title{
CARPENTED FUNCTIONALITIES: IMAGINARIES INTERCHANGE BETWEEN SCHOOL AND COMMUNITY
}

\begin{abstract}
The reflection contained in this work is the result of research carried out from 2011 to 2013, in a public school in the district of Igaraí, in the city of Mococa, interior of the state of São Paulo - Brazil, seeking possibilities of perception of the imaginary and functionalities built on and to the school unit, along with its actors and district. Using the documents produced by the school unit, documentary reference about the district and also the analysis of interviews given by actors involved in the constitution of school life, we find interpenetrated and asynchronous localities, whose own declared and imagined functionalities remained precariously under constant negotiations.
\end{abstract}

Keywords: school, functionality, imaginary 


\title{
FUNCIONALIDADES CARPINADAS: IMAGINARIOS CAMBIADOS ENTRE ESCUELA Y COMUNIDAD
}

\begin{abstract}
Resumèn
La reflexión contenida en este trabajo es resultado de una investigación realizada en el período de 2011 a 2013, en escuela pública del distrito de Igaraí, en la ciudad de Mococa, interior del Estado de São Paulo - Brasil, buscando posibilidades de percepción de imaginarios y funcionalidades erigidas sobre y, para la unidad escolar, junto a sus actores y distrito. En los documentos producidos por la unidad escolar, referencia documental sobre el distrito y también de análisis de entrevistas concedidas por actores involucrados en la constitución de la vida escolar, encontramos localidades interpenetradas y en movimientos diversos, asincrónicos, cuyas propias características declaradas e imaginadas se mantenían precariamente bajo constantes negociaciones.
\end{abstract}

Palabras clave: Escuela, funcionalidad, imaginarios.

\section{REFERÊNCIAS}

ARENDT, Hannah, Entre o passado e o futuro, São Paulo. Perspectiva, 2011.

BARDIN, Laurence, Análise de Conteúdo, São Paulo, Edições 70, 2011.

BAUMAN, Zygmunt, Comunidade: a busca por segurança no mundo atual. Rio de Janeiro: Zahar, 2003.

BENTHAM, Jeremy, (1789), Uma Introdução aos Princípios da Moral e da Legislação, São Paulo, Nova Cultural, 1989.

CAILLE, Alain. (2001), O princípio de razão, o utilitarismo e o antiutilitarismo, Brasil, Soc. estado, v. 16, n. 1-2, Dezembro.

CÂMARA MUNICIPAL DE MOCOCA, Requerimento $n^{0} 01423$ de 12 de dezembro de 2011. Empenho da Exma. Sra. Deputada Estadual, Heroilma Soares Tavares, visando o desmembramento dos Distritos de Igaraí e São Benedito das Areias/SP do Município de Mococa, visando a autonomia municipal destes. Requerente: José Francisco Ribeiro, http://camaramococa.sinoinformatica.com.br/sino/doResults.php?page=5\&tipo_atual=6\&prid ate $=2008-01-01 \&$ numero $=\&$ ano $=\&$ processo $=\& a n o \_$init $=2008-01-$

01\&ano_end=30/08/2012\&autor=\&outroautor=\&situacao=\&assunto=Igaraí\&tipo $1=1 \&$ tipo2= 2\&tipo3=3\&tipo4=4\&tipo5=\&tipo6=6\&tipo7=\&tipo8= , Última consulta em: 26 jan. 2013.

Requerimento no 01424 de 12 de dezembro de 2011.

Empenho do Exmo. Sr. Deputado Estadual, Campos Machado, visando o desmembramento dos Distritos de Igaraí e São Benedito das Areias/SP do Município de Mococa, visando a autonomia municipal destes. Requerente: José Francisco Ribeiro, http://camaramococa.sinoinformatica.com.br/sino/doResults.php?page=5\&tipo_atual=6\&prid ate $=2008-01-01 \&$ numero $=\&$ ano $=\&$ processo $=\&$ ano_init $=2008-01-$

01\&ano_end=30/08/2012\&autor=\&outroautor=\&situacao=\&assunto=Igaraí\&tipo1=1\&tipo2= 2\&tipo3=3\&tipo4=4\&tipo5=\&tipo6=6\&tipo7=\&tipo8= , Última consulta em: 26 jan. 2013.

Requerimento $n^{0} 01425$ de 12 de dezembro de 2011.

Empenho do Exmo. Sr. Deputado Estadual, Edson Ferrarini, visando o desmembramento dos Barbarói, Santa Cruz do Sul, n.53, p.<117-14O>,jan./jun. 2019 
Distritos de Igaraí e São Benedito das Areias/SP do Município de Mococa, visando a autonomia municipal destes. Requerente: José Francisco Ribeiro, http://camaramococa.sinoinformatica.com.br/sino/doResults.php?page=4\&tipo_atual=6\&prid ate $=2008-01-01 \&$ numero $=\&$ ano $=\&$ processo $=\&$ ano_init $=2008-01-$

$01 \&$ ano_end=30/08/2012\&autor=\&outroautor $=\&$ situacao $=\&$ assunto=Igaraí $\&$ tipo $1=1 \&$ tipo $2=$ 2\&tipo3=3\&tipo4=4\&tipo5=\&tipo6=6\&tipo7=\&tipo8= Ultima consulta em: 26 jan. 2013.

Requerimento $\mathrm{n}^{\mathrm{o}} 01426$ de 12 de dezembro de 2011. Empenho do Exmo. Sr. Deputado Estadual, Roque Barbiere, visando o desmembramento dos Distritos de Igaraí e São Benedito das Areias/SP do Município de Mococa, visando a autonomia municipal destes. Requerente: José Francisco Ribeiro.

http://camaramococa.sinoinformatica.com.br/sino/doResults.php?page=4\&tipo_atual=6\&prid ate $=2008-01-01 \&$ numero $=\&$ ano $=\&$ processo $=\&$ ano $\_$init $=2008-01-$

$01 \&$ ano_end $=30 / 08 / 2012 \&$ autor $=\&$ outroautor $=\&$ situacao $=\&$ assunto=Igaraí $\&$ tipo $1=1 \&$ tipo $2=$ 2\&tipo3=3\&tipo4=4\&tipo5=\&tipo6=6\&tipo7=\&tipo8=, Ultima consulta em: 26 jan. 2013.

CARTÓRIO ELEITORAL DE MOCOCA. Boletim de distribuição do eleitorado por local de votação de 24 de agosto de 2012. Mococa, 2012.

CASTORIADIS, Cornelius, ROUANET, Sérgio Paulo, CHAUÍ, Marilena, TORRES, João Carlos Brum, ROSENFIELD, Dênis, A criação histórica. Porto Alegre, Artes e Ofícios. 1992.

CASTORIADIS, Cornelius, A instituição imaginária da sociedade, Rio de Janeiro, Paz e Terra, 1982.

Janeiro: Paz e Terra, 1987.

As encruzilhadas do labirinto 2: os domínios do homem. Rio de

ESCOLA ESTAdUAL JOÃO DE MOURA, Livro de Atas do Conselho de Escola. Igaraí Mococa. 2000.

Ofício $n^{0} 545$ de 14 de maio de 2012 Referente a quadro funcional de unidade escolar, Igaraí - Mococa, 2012.

Projeto Político Pedagógico 2007 - 2010. Igaraí - Mococa,

2007.

, Projeto Político Pedagógico 2011 - 2014. Igaraí - Mococa,

2011.

FREITAS, Edgard, Mococa 100 anos de história: 1847 - 1947, Edição de Autor, 1948.

IBGE (Instituto Brasileiro de Geografia e Estatítisca), Mococa 2010,

http://www.ibge.gov.br/cidadesat/painel/painel.php?codmun=353050, Última consulta em 28 de agosto de 2012.

LEEDS, Anthony, Elizabeth Leeds, A sociologia do Brasil urbano, Rio de Janeiro, Zahar Editores, 1978. 
LOSADA, Manuel, Imaginário radical: a proposta de castoriadis à atual crise dos paradigmas no campo das ciências naturais e sociais, Brasil, Boletim Interfaces da Psicologia da UFRuralRJ. v.2, n. 1, Junho, 2009.

MAGNANI, José Guilherme Cantor, Etnografia como prática e experiência, Brasil, Horiz. antropol., Porto Alegre, v. 15, n. 32, Dezembro, 2009.

NADAL, Beatriz Gomes, Cultura escolar: um olhar sobre vida na escola. São Paulo, Pontifícia Universidade Católica de São Paulo, tese de Doutorado, 2008.

PALADINI, Carlos Alberto, Assim Nasceu Mococa. São Paulo, Alfa Omega, 1995.

QUEIROZ, Humberto, Mococa: da sua fundação até 1900. São Paulo, Typographia do Diário Official, 1913

SÃO PAULO, Decreto Estadual no 17.698 de 07 de julho de 1949. Constitui Grupo Escolar de Igaraí. Diário Oficial do Estado de São Paulo, 1949.

Decreto Estadual no 11.794 de 28 de junho de 1978. Autoriza doação de terreno necessário à construção de Escola de Primeiro Grau de Igaraí.

http://dobuscadireta.imprensaoficial.com.br/default.aspx?DataPublicacao=19780629\&Cadern o=Poder Executivo\&NumeroPagina=2 ,Última consulta em: 27 de jan. de 2013.

SENNETT, Richard, Autoridade, Rio de Janeiro, Record, 2001.

Bestbolso, 2008.

Carne e pedra: o corpo e a cidade na civilização ocidental, Rio de Janeiro,

Respeito: a formação do caráter em um mundo desigual, Rio de Janeiro,

Record, 2004.

SILVA, Joyce Mary Adam Paula, Cultura escolar, autoridade, hierarquia e participação: alguns elementos para a reflexão, Brasil, Cadernos de Pesquisa, n $^{\circ}$ 112, maio, 2001.

Data de recebimento: $25 / 07 / 2018$

Data de aceite: 03/09/2019

\section{Sobre os autores:}

Luciano Plez Melo é Doutor em Educação. Endereço Eletrônico: luciano.plez@gmail.com

Leila Maria Ferreira Salles é Doutora em Educação (Psicologia da Educação) pela Pontifícia Universidade Católica de São Paulo, professora voluntaria da pós-graduação da Universidade Estadual Paulista Júlio de Mesquita Filho, UNESP - RC. Endereço Eletrônico: leila@rc.unesp.br 